\title{
Detecting of the Risk Indicator Parameters of Radioactive Nuclides Around the Stores of Fertilizer and Pesticides, Al Jazeera Agricultural Project Using the Germanium Detector
}

\author{
Hafiz Fatelrahman Babeker Fadl Alla, Mahmoud Hamid Mahmoud Hilo, \\ Ahmed Al Hassan Alfaki, Ahmed Mohamed Salih Hamid \\ Department of Physics, Faculty of Science, Sudan University of Science and Technology, Khartoum, Sudan
}

Email address:

hafizfath@gmail.com (H. F. B. F. Alla),mahmoudhilo@gmail.com (M. H. M. Hilo)

To cite this article:

Hafiz Fatelrahman Babeker Fadl Alla, Mahmoud Hamid Mahmoud Hilo, Ahmed Al Hassan Alfaki, Ahmed Mohamed Salih Hamid. Detecting of the Risk Indicator Parameters of Radioactive Nuclides Around the Stores of Fertilizer and Pesticides, Al Jazeera Agricultural Project Using the Germanium Detector. International Journal of High Energy Physics. Vol. 8, No. 1, 2021, pp. 13-18.

doi: $10.11648 /$ j.ijhep.20210801.12

Received: May 24, 2021; Accepted: July 6, 2021; Published: September 11, 2021

\begin{abstract}
This study shows the assessment of radiation hazard parameters due to terrestrial radionuclide's in soil around the residential areas near the stores of fertilizer and pesticides, Al Jazeera agricultural project Radiation hazard parameters were was computed. These include excess lifetime cancer risk, annual gonadal dose equivalent hazard index, radium equivalent activity and external hazard. Obtained result indicates that some of the radiation hazard parameters, the average value excess lifetime cancer risk (ELCR) $0.12 \times 10^{-3} \mu \mathrm{Sv}$, were found to be lower than the UNSCEAR reported value of $0.29 \times 10^{-3} \mu \mathrm{Sv}$ (UNSCEAR 2000), and that of average annual gonadal dose equivalent hazard index $214.59 \mu \mathrm{SVyear}^{-1}$, the average value of AGDE in the region is the lower than worldwide average of $300 \mu \mathrm{Sv} / \mathrm{y}$ (UNSCEAR 2000). the average radium equivalent $\mathrm{Ra} \mathrm{e}_{\mathrm{eq}}$ $\left(\mathrm{Bqkg}^{-1}\right) 64.3 \mathrm{Bqkg}^{-1}$. The average external hazard index $\left(\mathrm{H}_{\mathrm{ex}}\right) 0.18$, the calculated $\mathrm{H}_{\mathrm{ex}}$ values for all the samples were found to be below unity, which does not cause harm to the populations of the investigated region. Radiation hazard parameters due to terrestrial radionuclide's in the soil samples were compared to the international values reported by United Nations Scientific Committee on the Effects of Atomic Radiation (UNSCEAR, 2000) and previous studies on the region.
\end{abstract}

Keywords: Radiation Hazard, Stores, Fertilizer and Pesticides, Excess Lifetime Cancer Risk (ELCR), External Hazard ( $\left.\mathrm{H}_{\mathrm{ex}}\right)$

\section{Introduction}

To obtain information about the levels of harmful pollutants that are found in the same environment in which living organisms live so it is necessary to understand the evolution of natural radionuclide's in the surrounding environment all this information is used for the presence of signs related to radiological assessments in the environment unstable radionuclide's that occur naturally in Earth's fixed core crust from which natural ionizing radiation is produced from nuclear transformations that occur spontaneously [1]. The pesticide can reach the human through the skin, mouth or breathing which requires wearing protective clothing. The pesticide can also reach the pet by skin or mouth by eating or drinking pesticide-contaminated substances, Farmers who use fertilizers in agriculture and workers who work in the production of fertilizers and pesticides are exposed to gamma radiation which is external exposure to radiation as well as alpha particles, which expose the internal human body to radiation emitted by the radionuclide's of the uranium, thorium and potassium series when inhaling radon and its strain that produces alpha particles that The human body is exposed to it internally which leads to lung cancer when the dose reaches the respiratory system directly [2]. Serious health effects on human health from chronic and deadly diseases from cancer in the blood and lung and this occurs when radionuclide's reach the human respiratory system [3]. For environmental laws that do not exist enforcement contrary to different areas and penalties are usually insufficient to ensure compliance and thus promoted by the continuation of the first growth mentality and the judicial system remains largely "unable to provide strong protection of environmental rights against violations [4]. 
Studying the natural radioactivity in the soil to assess the radiation dose to which humans are exposed which causes future health risks in the environment surrounding the population and because of the changes that occur in the environment natural radioactive materials can reach dangerous levels in certain circumstances $[1,5]$. Therefore, radiation emitted from fertilizer has the potential to When farmers and workers are exposed to a high level of use of fertilizers and pesticides the natural radioactivity in fertilizers and pesticides must be monitored which is very important for human protection in accordance with the Natural Radiation Protection Law [6]. Ground radiation in the soil may be dangerous to people, depending on ways of transmission to people, and internal and external exposure to gamma rays, therefore it is very necessary to assess the concentration of the natural radionuclide's in soil and water [7]. as well as petroleum industries is the largest consumer of radioactive materials and also radiography in the field of medicine and industry Some of the healthy practices of workers and manufacturers of pesticides and fertilizers do not tell the farmers that these products are subject to chemical reactions in the soil which leads to serious side effects on the environment in general and its contents of water, soil and air and from the negative and harmful effects caused by the pollution of fertilizers and pesticides in agricultural lands produced due to nitrogen fertilizers industrial calcium and magnesium [8]. Artificial radionuclides is nuclear weapons testing the high doses of radiation that occur to workers farmers and residents in a certain environment are natural sources of radiation and this is from isotopes of radioactive elements that are found in nature such as uranium, throium and potassium and their daughters [3]. Although there is an element of natural uranium in the surrounding environment to humans and the most natural use of materials and by the presence of the organism which is called a series of radioactive decay which includes a large amount of radioactive elements [9]. Phosphates found in nature contain a number of radioactive and stable elements of great importance in the population environment for the manufacture of phosphate fertilizers. Phosphate rocks form the largest part of the rocks and some of the phosphorous elements present in abundance in the rocks $[10,11]$.

\section{Effective of the Soil Pollution}

Microbial community composition can result in the introduction of contaminated soil ecosystem to several types of general and specific changes in the composition of microbial community. It is the function of contaminated concentration, duration of exposure, and the ability of a compound to be analyzed [12]. Cultivation of different crops systems provide The economic benefits that accrue to the agricultural soil are represented in the alternating agricultural rotations of the crops that are grown on it, which reduces the negative effects on the surrounding ecosystem as well as reducing plowing and good management of agricultural land which makes the soil good and suitable of positive on the ecosystems of the soil $[13,14]$. Interference of radioactive terrestrial and cosmic radionuclides into the Chemicals harmful to human health are affected by eating, drinking and inhaling the air which is the most common way to endanger human life the use of radionuclides and eliminated by the body during normal metabolism. Some of radionuclide's degrade quickly but is replaced by inhalation or fresh inhalation. Degrade other radionuclide's more slowly have been concentrated in specific tissues of the body (such as radium in the bones); others are not easily absorbed by the gastrointestinal tract and is eliminated quickly [15].

Since the beginning of the twentieth century, the focus on agriculture indiscriminately has affected the soil, air and water and environment surrounding humans and the deterioration of biodiversity with the increase in population density in societies which led to the impact on human life in those societies which was predicted by the International Commission for the Protection of Radiation [16]. Developed countries contain the largest amount of e-waste hazardous to humans including India, Pakistan the Philippines and Malaysia and the largest exporter and importer of radioactive e-waste is China which receives more than seventy percent of e-waste exported from developing countries $[17,18]$.

\section{Effective Water Pollution}

While the water pollution began to receive the attention it deserves the contribution of the agriculture requires more attention because the current agricultural practices have an impact on the unprecedented of water quality. In some highincome countries it have overtaken agriculture pollution from the settlements and built a leading factor in the eutrophication in land, coastal waters and contamination of the groundwater with nitrates and salts, and it can contribute to agriculture increased due to pollution to several fundamental factors including population growth changes in Demand for food, fuel and climate change [19]. Focused study of surface water pollution in the first place on the streams and lakes have been most of the scientific tools developed by the regulatory agencies such as US Environmental Protection Agency to the protect quality of water in this region of surface of Earth water applications. Water stored in reservoirs and lakes well as water flowing permanently in tables are subject to severe pressure, and they are used in water, agriculture, industry and entertainment supplies, can easily contaminate the water [20].

\section{Fate and Distribution of Radionuclide's in the Environment}

Metal dispersion can be in the soil, water and air. Minerals in the aquatic environment, soil and agricultural dispersed in surface water, sediment, by stability in the sediment and suspension Kdzeiat in surface water. In the case of surface water and groundwater sediment and air availability. The bioavailability is a complex function of many factors 
including total concentration characteristics (physical \& chemical forms) for the metals [21].

Radiation comes from outer space, from the ground and even inside our bodies. Radiation exists around us and was present since the birth of the planet. This type of radiation is called background radiation. Emitting background radiation (which scientists called "background radiation everywhere") of each of the radioactive chemicals of natural and human (radionuclide's) There are some radionuclides naturally occurring in the ground down our feet, while in the atmosphere is produced by some other radiation from space. Entered the radionuclides of man-made in the environment through activities such as medical procedures used radionuclides to depict the body and generate electricity that use radioactive uranium as fuel [15]. Increasing awareness of the environmental protection from radiation among the workers in mining site is necessary to enhance safety and the health. This is particularly important as a result of the natural evolution in different areas of the scientific research for a better life. Human evolution is constantly looking into ground to check the secrets of the universe and increase their wealth [22].

\section{Radionuclide in Body}

Interference of the radioactive terrestrial and the cosmic radionuclide's into the body through food we eat, the water we drink and the air we breathe as with all chemicals the use of radionuclide's and eliminated by the body during normal metabolism. Some of radionuclides degrade quickly but is replaced by inhalation or fresh inhalation. Degrade other radionuclide's more slowly have been concentrated in specific tissues of the body (such as radium in the bones); others are not easily absorbed by the gastrointestinal tract and is eliminated quickly [15].

Direct absorption through aerial parts of the plants. These radionuclide's when they accumulate over period of time in food and water natural way direct exposure to population of human beings their are consumption [23].

The radiation detection devices developed against the necks of people measured exposure rates due to emissions resulting from radioactive decay of gamma irradiation for ${ }^{131} \mathrm{I}$ in the thyroid gland. Because of contamination of external and internal radiation of persons subject to control, gamma radiation contributed to many of the radionuclide's in different locations in the high exposure rates recorded by detectors. To accurately estimate contribution of emissions from the various internal and external parts of the body gamma rays [24].

\section{Effect of Radiation on Human}

Radioactive substances naturally occurring representing approximately $80 \%$ of human exposure to natural radiation which its second leading cause of cancer after tobacco, The long-term uranium exposure through the inhalation has many health effects such as the chronic lung disease and the anemia leukopenia and necrosis of mouth, Causes radium, bone tumors and cranial nasal [21].

Heavy metals can pose a potential threat to the human health through. The chronic exposure to contaminated soil particles and consumption of contaminated crops and it reported that heavy metal contamination in soil can promote the causes of mouth cancer. Calculated risk index based on the food consumption, ingestion of soil and absorb much higher than one skin, which indicates the presence of an adverse health effect is obvious on the population. $87.5 \%$ of risk came from eating and $10.5 \%$ of skin absorption and the remaining $2 \%$ resulting from the ingestion of soil [25]. Resulted in the accumulation of the toxic chemical contaminants and the pathogens in soil-borne soil to increase the human exposure either through the inhalation or skin contact or ingestion of the soil or indirect exposure through food intake or drinking waters. Therefore it is important to develop tools to assess potential human exposure to the pollutants and to determine concentrations of the risk threshold meaningful in soil in order to protect human health $[26,27]$. Constitute a serious contaminant fertilizer where it is washed in the rain or flooding rivers and various tables. Most fertilizers contain phosphate products, potassium and nitrate. This material nutrient for plants, but some of them constitute a serious health hazard especially infants, due to the intervention of the chemical in the transfer of oxygen in the blood [15].

Radiation leads to the human or any other material tissue damage through ionization of the atoms. Ionizing radiation absorbed by the human tissue has enough energy to remove electrons from the atoms that make up the tissue molecule. Very simple terms when an electron is the shared by the atoms that is form a molecular association is broken association offset, and breaks down the molecule. This process may occur by the "injury" directly to these atoms or may result indirectly free radical formation due to the irradiation of the neighboring molecule. The most sensitive in the cell structure is the DNA molecule which carries the genetic blueprint of the cell and indeed the whole of the object. If damage is not repaired radioactive DNA the cells fail to survive or reproduce. If the cells remain insufficient loss of tissue or organ function may occur. Alternatively may be repairing the damage is incomplete or incorrect until the cells continue to divide, but to turn cancerous [16]. They also have the attention of agricultural researchers around the world because of their ability to maintain quality and quantity of production at high levels at one time with the limit. The environmental footprint of the agriculture and support sustainable agriculture in tropical and the temperate regions [16]. Alpha particles interact strongly with the human tissue through transfer of energy. beta interact strongly less than alpha particles which allow them to travel farther through tissue before the transfer of energy particles. The difference between effects of the alpha particles and beta particles is concentration of tissue damage. Alpha particles can be damage many of molecules on a short distance while beta particles may damage the particles scattered over a 
greater distances. The extent of damage depend on energy of emitted alpha particles or individual beta particle [28].

\section{Material and Methods}

\subsection{The Study Area}

Fertilizers and pesticides stores are located in Al-Jazeera agricultural project west of Al-Hassa city, and in Qureshi station, $4 \mathrm{~km}$ north of Al-Hassa city. These stores are located on an area of about 2 kilometers from the land, and the number of these stores about eight stores very large area of one store $40 \mathrm{~m}$ in 120 and at a height of approximately six meters, and the distance between each Jabalon and the other approximately 20 meters, These stores have a wall from the north and south side only, but from the west side and the way does not have a wall, as well as there are some residential areas very close to them as a Qurashi station located 500 meters from these stores in the south-west of these stores, while the other residential areas farther compared In Qurashi Station Area, There are also some random places that are almost adhered to these stores and used for food and tea vendors for the workers of these stores and those who cross the road, and owners of heavy vehicles located in that place.

\subsection{Preparation of the Samples}

80 soil samples were randomly taken from four locations in a direction north, south, east and west for pesticide and fertilizer stores for Al-Jazeera agricultural project near Al-hasahisa city in Al-Jazeera state, Sudan, using Oker soil sampling device (20-25) $\mathrm{cm}$ deep in the ground to obtain natural soil. Sampling locations were determined approximately 200 meters for each direction from the source. $0.5 \mathrm{~kg}$ was taken for each sample from the four sides of the source. The samples were sorted and weighted to obtained a homogeneous fine powders. The samples were then placed with half a kilogram in Marinelli beakers, and the beakers were sealed to about 4 weeks. To reach secular equilibrium between thorium and radium contents of sample and their daughters [29].

\subsection{The Instruments}

High purity germanium (HPGe) P-type coaxial detector GCD30185X. Model with 37\% relative efficiency and multichannel analyzer unit with 16384 channels manufactured by Baltic Scientific Instrument company. Energy resolution (full width at half maximum) of this detector is $1.95 \mathrm{keV}$ for gamma energy line at $1332.520 \mathrm{keV}$ photons of ${ }^{60} \mathrm{Co}$. The system was calibrated and the calibration quality control was carried out by using soil standard reference materials (IAEA226 and IAEA-375) whose concentration of the natural radioactivity has been certified by the IAEA.

\subsection{Samples Analysis}

The soil samples were crushed into a fine powder and sieved. The samples were then sealed in 500-ml plastic containers for approximately 4 weeks to allow radon (half- life 3.8 days) and its short-lived decay daughters ${ }^{214} \mathrm{Bi} \&{ }^{214} \mathrm{~Pb}$ to reach secular equilibrium with the long-lived ${ }^{226} \mathrm{Ra}$. The sample weights ranged to $500 \mathrm{~g}$, and the background sample was also prepared using a similar empty container. The multichannel analyzer which was used for data acquisition and analysis of the gamma spectra. The spectrometer was tested for its linearity and then calibrated for energy using gamma sources supplied by the International Atomic Energy Agency Vienna. This was achieved by collection of spectra data from standard sources with energies in range of 0.25 2.62 MeV. The channel numbers of the photo peaks corresponding to different gamma energies were recorded after 900 seconds and the energy-channel linear relationship was obtained [24].

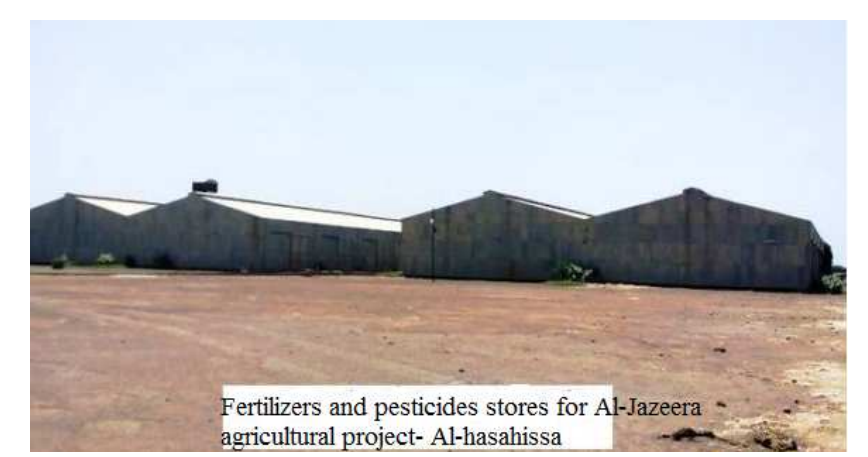

Figure 1. Map of fertilizer stores and pesticides Al-Jazeera agricultural project.

\section{Computation of Radiation Hazard Parameters}

\subsection{The Excess Life Time Cancer Risk (ELCR)}

ELCR was estimated by using equation (1)

$$
\mathrm{ELCR}=\mathrm{E} \times \mathrm{DL} \times \mathrm{RF}
$$

Here DL is the life expectancy 63 year for Sudan, (WHO 2015) and RF is the cancer risk factor for each Sievert which is randomly assessed by the International Commission on Radiological Protection (ICRP) (1990) at 0.05 for the public [30].

\subsection{The Annual Gonadal Dose Equivalent (AGDE)}

The AGDE was computed from ${ }^{238} \mathrm{U},{ }^{232} \mathrm{Th}$ and ${ }^{40} \mathrm{~K}$ activity by using equation (2) [3].

$$
\operatorname{AGDE}(\mu \mathrm{Sv} / \text { year })=3.09 \mathrm{~A}_{\mathrm{Ra}}+4.18 \mathrm{~A}_{\mathrm{Th}}+0.314 \mathrm{~A}_{\mathrm{K}}
$$

\subsection{The Radium Equivalent Activity $\left(R a_{e q}\right)$}

Radium equivalent in $\left(\mathrm{Bq} \mathrm{kg}^{-1}\right)$ was calculated from equation (3)

$$
\mathrm{Ra}_{\mathrm{eq}}=\mathrm{A}_{\mathrm{Ra}}+1.43 \mathrm{~A}_{\mathrm{Th}}+0.077 \mathrm{~A}_{\mathrm{K}}
$$

where $A_{R a}, A_{T h}$ and $A_{K}$ are activity concentrations in $(B q$ $\left.\mathrm{kg}^{-1}\right)$ of ${ }^{226} \mathrm{Ra}\left({ }^{238} \mathrm{U}\right),{ }^{232} \mathrm{Th}$ and ${ }^{40} \mathrm{~K}$ respectively. 


\subsection{The External Hazard Index $\left(H_{e x}\right)$}

The radiation exposure due to ${ }^{226} \mathrm{Ra},{ }^{232} \mathrm{Th}$ and ${ }^{40} \mathrm{~K}$ may be external. This hazard defined in terms of external hazard index or indoor radiation hazard index and denoted by $\mathrm{H}_{\mathrm{ex}}$ can be calculated using the equation (4).

$$
\mathrm{H}_{\mathrm{ex}}=\mathrm{A}_{\mathrm{Ra}} / 370+\mathrm{A}_{\mathrm{Th}} / 259+\mathrm{A}_{\mathrm{K}} / 9810
$$

Where $A_{R a}, A_{T h}$ and $A_{K}$ are activity concentrations $\left(\mathrm{Bqkg}^{-1}\right)$ of radium, thorium and potassium respectively as obtained in the analyzed samples. The value of this index should be less than $1 \mathrm{mSvy}^{-1}$ in order for the radiation to be considered acceptable to the public [25].

\section{Result and Discussion}

The estimate of the rate of cancer risk by calculating excess life time cancer risk (ELCR) \pm standard deviation $(0.12 \pm 0.01) \times 10^{-3} \mu \mathrm{SV}$, with the minimum value being 0.09 $\times 10^{-3} \mu \mathrm{SV}$ and the maximum $0.14 \times 10^{-3} \mu \mathrm{SV}$. The excess lifetime cancer risk values, in this study, were found to be lower than the UNSCEAR reported value of $0.29 \times 10^{-3} \mu \mathrm{SV}$ (UNSCEAR 2000) [31].

The average annual gonadal dose the equivalent hazard index (AGDE) \pm standard deviation $(214.59 \pm 18.62)$ $\mu$ SVyear $^{-1}$, with minimum value being $168.97 \mu$ SVyear $^{-1}$ and maximum $261.17 \mu \mathrm{SVyear}^{-1}$. The average value of the AGDE in both regions is lower than the worldwide average of 300 $\mu$ Sv/y (UNSCEAR 2000) [31].

The average radium equivalent $\mathrm{Ra}_{\mathrm{eq}}\left(\mathrm{Bqkg}^{-1}\right) \pm$ standard deviation $(64.3 \pm 5.99) \mathrm{Bqkg}^{-1}$, with minimum value being $50.06 \mathrm{Bqkg}^{-1}$ and maximum $79.88 \mathrm{Bqkg}^{-1}$.

And the average external hazard index $\left(\mathrm{H}_{\mathrm{ex}}\right) \pm$ standard deviation $(0.18 \pm 0.02)$ with the minimum value being 0.14 and the maximum 0.22 The calculated $\mathrm{H}_{\mathrm{ex}}$ values for all samples were found to be below unity which does not cause harm to the populations of the investigated region.

\section{Conclusion}

In conclusion of this paper the concentration of radioactivity of nuclides radium 226, radium 228, thorium 232 and cesium 137 around the stores of fertilizers and pesticides for the AlJazeera agricultural project in Hasahisa area.

it was found that the values that we reached for estimates of average life time cancer risk of developing were very small compared to the average UN global value for atomic radiation protection, and the average value of the Annual gonadal dose equivalent is less than the average global value, and this indicates that the distribution of radionuclide's in The samples for this region have a normal distribution, as well as for the Radium equivalent activity, external hazard index, well below the global average readings. This indicates that the distribution of radionuclide's in soil samples for that region is normal.

In order to protect human health and the environment from the harmful effects of radionuclide's that result from the imposed use of fertilizers and pesticides on the soil, the supervisory authorities in the field of radiation protection must develop devices in the field and raise awareness of the optimal use of fertilizers and not overuse them.

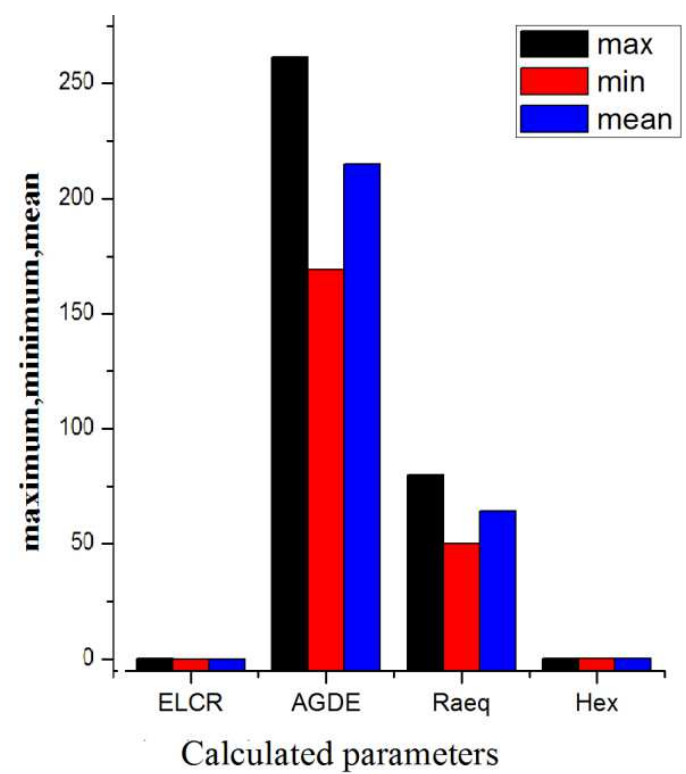

Figure 2. Statistical summary of risk indicator parameters: excess life time cancer risk ELCR, annual gonadal dose equivalent hazard index $A G D E(\mu S v$ year-1), radium equivalent Raeq (Bq kg-1) and external hazard index Hex.

\section{References}

[1] Chauhan P, Chauhan RP. Variation in alpha radioactivity of plants with the use of different fertilizers and radon measurement in fertilized soil samples. Journal of Environmental Health Science and Engineering. (2014), 1 (12): 70 .

[2] N. M. Hassan, N. A. Mansour, M. Fayez-Hassan, and S. Fares, "Assessment of radiation hazards due to exposure to radionuclides in marble and ceramic commonly used as decorative building materials in Egypt," Indoor and Built Environment. (2017), 26 (3): 317-326.

[3] Isinkaye MO, Emelue HU. Natural radioactivity measurements and evaluation of radiological hazards in sediment of Oguta Lake, South East Nigeria. Journal of Radiation Research and Applied Sciences. (2015), 8 (3): 459-469.

[4] Smith, Laurence, et al. "Mitigation of diffuse water pollution from agriculture in England and China, and the scope for policy transfer. J " Land Use Policy (2017): 61, 208-219.

[5] Pooja Chauhan, Rishi Pal Chauhan. "Variation in alpha radioactivity of plants with the use of different fertilizers and radon measurement in fertilized soil samples", Journal of Environmental Health Science and Engineering, 2014.

[6] Hassan NM, Chang BU, Tokonami S. Comparison of Natural Radioactivity of Commonly Used Fertilizer Materials in Egypt and Japan. Journal of Chemistry. (2017), 2017: 1-9.

[7] Alnassar NA, Jaafar MS, Kabir NA. Determination of Concentrations of Natural Radionuclides in Soils and Water in Non-cultivated Sites in Seberang Perai, Malaysia J. of Applied Physics. (2017), 9 (2): 27-35. 
[8] Faweya EB, Ayeni MJ, Olowomofe GO, Akande HT. Estimation of radiation exposure in soils and organic (animal) and inorganic (chemical) fertilizers using active technique. International Journal of Environmental Science and Technology. (2017), 14: 1-16.

[9] I. H. Saleh, A. A. Abdel-Halim. "Determination of depleted uranium using a high-resolution gammaray spectrometer and its applications in soil and sediments", Journal of Taibah University for Science, 2018.

[10] El-Bahi SM, Sroor A, Mohamed GY, El-Gendy NS. Radiological impact of natural radioactivity in Egyptian phosphate rocks, phosphogypsum and phosphate fertilizers. Applied Radiation and Isotopes. (2017), 123: 121-127.

[11] P. O. Ogunleye, M. C. Mayaki, I. Y. Amapu."Radioactivity and heavy metal composition of Nigerian phosphate rocks: possible environmental implications", Journal of Environmental Radioactivity, 2002.

[12] MORGADO, Rui G.; LOUREIRO, Susana; GONZÁlEZALCARAZ, Maria N. Changes in Soil Ecosystem Structure and Functions Due to Soil Contamination. In: Soil Pollution. Academic Press, 2018. p. 59-87.

[13] Arriaga, F. J., Guzman, J., \& Lowery, B. (2017). Conventional Agricultural Production Systems and Soil Functions. In Soil Health and Intensification of Agroecosytems (pp. 109-125). Academic Press.

[14] Francisco J. Arriaga, Jose Guzman, Birl Lowery. "Conventional Agricultural Production Systems and Soil Functions", Elsevier BV, 2017.

[15] NAJIB, M. U., et al. Radiological Assessment of Sediment of Zobe Dam Dutsinma, Katsina State, Northern Nigerian. Am J Eng Res, 2016, 5. 3: 51.

[16] PAVLIDIS, George; TSIHRINTZIS, Vassilios A. Environmental benefits and control of pollution to surface water and groundwater by agroforestry systems: a review. Water resources management, 2018, 32. 1: 1-29.

[17] CHAKRABORTY, Paromita, et al. Biochar for Effective Cleaning of Contaminated Dumpsite Soil: A Sustainable and Cost-Effective Remediation Technique for Developing Nations. In: Environmental Biotechnology: For Sustainable Future. Springer, Singapore, 2019. p. 3-29.

[18] Environmental Biotechnology: For Sustainable Future", Springer Science and Business Media LLC, 2019.

[19] EVANS, Alexandra EV, et al. Agricultural water pollution: key knowledge gaps and research needs. Current opinion in environmental sustainability, 2019, 36: 20-27.
[20] WALKER, D. B., et al. Surface water pollution. In: Environmental and pollution science. Academic Press, 2019. p. 261-292.

[21] KLU, PROSPER KWAME. Assessment Of Health Risks Due To Toxic Metals And Naturally Occurring Radioactive Materials In The Birim River In East Akim Municipality Of The Eastern Region Ghana. 2015. PhD Thesis. University of Ghana.

[22] IDRISS, Hajo, et al. Health risk profile for terrestrial radionuclides in soil around artisanal gold mining area at Alsopag, Sudan. Acta Geophysica, 2018, 66. 4: 673-681.

[23] MUSTAKIM, Rumman, et al. Natural Radionuclide's Concentrations and Annual Effective Dose in Seasonal Fruits of Bangladesh. Nuclear Science, 2018, 3. 3: 28.

[24] KUTSEN, Semion, et al. Influence of the external and internal radioactive contamination of the body and the clothes on the results of the thyroidal 131 I measurements conducted in Belarus after the Chernobyl accident-Part 2: Monte Carlo simulation of response of detectors near the thyroid. Radiation and environmental biophysics, 2019, 58. 2: 215-226.

[25] HUANG, Ying, et al. Heavy metal pollution and health risk assessment of agricultural soils in a typical peri-urban area in southeast China. Journal of environmental management, 2018, 207: $159-168$

[26] MERDANOĞLU, B.; ALTINSOY, N. Radioactivity concentrations and dose assessment for soil samples from Kestanbol granite area, Turkey. Radiation Protection Dosimetry, 2006, 121. 4: 399-405.

[27] Sónia M. Rodrigues, Paul F. A. M. Römkens. "Human Health Risks and Soil Pollution", Elsevier BV, 2018.

[28] KISS, J. J.; DE JONG, E.; BETTANY, J. R. The distribution of natural radionuclides in native soils of southern Saskatchewan, Canada. Journal of environmental quality, 1988, 17. 3: 437-445.

[29] DIAB, H. M., et al. Evaluation of natural radioactivity in a cultivated area around a fertilizer factory. Journal of Nuclear and Radiation physics, 2008, 3. 1: 53-62.

[30] IDRISS, Hajo, et al. Environmental impact assessment of natural radioactivity around a traditional mining area in $\mathrm{Al}$ Ibedia, Sudan. Archives of environmental contamination and toxicology, 2016, 70. 4: 783-792.

[31] UNSCEAR. (2000). Sources and effects of ionizing radiation. United Nations scientific committee on the effects of atomic radiation. New York, USA: United Nations Publication. 